\title{
La Problemática de la Cerámica Ychsma: El Estado de la Situación y Algunos Elementos de Discusión
}

\section{The problematic of theYchsma ceramics: the state of the situation and some elements of discussion}

Francisco Vallejo Berríos ${ }^{\mathrm{I}}$

\section{RESUMEN}

El presente artículo intenta esbozar una serie de problemas existentes en torno al manejo de la cerámica ychsma, especialmente en la definición de su unidad estilística, secuencia y distribución, basándose en las nuevas investigaciones realizadas en los valles del Rimac y del Lurin, asi como aquellos otros estudios esenciales para entender a la sociedad Ychsma en su conjunto. Elementos tales como territorio, etnicidad y la presentación de algunos contextos arqueológicos ychsma, sirven de marco para incorporar una discusión sobre los criterios arqueológicos utilizados para la definición de la secuencia cerámica Ychsma, asi como para incorporar al debate algunos argumentos adicionales sobre la misma.

Palabras clave: Ychsma; cerámica ychsma; secuencia cerámica; costa central peruana.

\section{Abstract}

This paper tries to outline the problems related to the use of the Ychsma pottery, in particular with the definition of its stylistic unity, sequence, and distribution based in recent research at the Rimac and Lurin valleys and other essential contributions to un- 
derstand the Ychsma society as a whole. Elements like territory and ethnicity and some ychsma archaeological contexts are the frame of a brief discussion about the archaeological criteria used to define the ychsma ceramic sequence, and also to incorporate to the debate additional arguments.

Key Words: Ychsma; ychsma pottery; sequence pottery; Peruvian central coast.

\section{Problemática general}

En general, la problemática de la cerámica ychsma ha girado y gira en torno a tres grandes factores: el corpus cerámico, la secuencia y la distribución geográfica. Por el corpus cerámico, entendemos todo el conjunto de formas y tipos cerámicos que han sido utilizados por la sociedad Ychsma. Este conjunto, propiamente material, tiene dos expresiones objetivas: su ubicación en el tiempo, es decir lo que los arqueólogos llamaríamos secuencia, y su ubicación en el espacio, lo que llamamos distribución geográfica.

Una revisión rápida de las principales investigaciones que tratan sobre la cerámica ychsma o sus afines terminológicos, hace ver que todavía no existe uniformidad en los planteamientos generales. De hecho, la comprensión misma del estilo Ychsma y sus componentes cerámicos es abordado de diferentes maneras surgiendo, o aún utilizándose, términos estilísticos paralelos o restrictivos a algunos elementos cerámicos, como ocurre con las denominaciones de "Huancho" o de "Puerto Viejo", por citar las más conocidas.

Luego de la definición etnohistórica del término (Rostworowski 1972, 1978) y el trabajo de Bazán Del Campo (1990), diversos investigadores aún continuaron utilizando terminologías obsoletas o limitantes como las ya citadas de "Huancho" (Ravines 2000) y "Puerto Viejo" (Makowski y Vega Centeno 2004; Ángeles 2003; Tantaleán y Pinedo 2004). Incluso varios tipos cerámicos Ychsma fueron catalogados como pertenecientes a otros estilos foráneos, como el Chincha (Isla 1995). En varios casos, al carecerse de un criterio uniforme sobre el estilo Ychsma, proliferó también la saturación de términos estilísticos basados en algunos rasgos tecnológicos o decorativos, como los de Negro sobre Blanco (Paredes y Ramos 1994), Lurín Orange (Eeckhout 1999), Lurín Negro (Makowski 2003) y Estilo Llano (Franco 2004), entre otros. 
Como bien han señalado recientemente Feltham y Eeckhout (2004: 646), las clasificaciones anteriores realizadas han apuntado demasiado al uso de la fragmentería cerámica, sin tomar en cuenta el riesgo que esto conlleva, pues varios de los elementos "clasificatorios", tanto decorativos como tecnológicos usados mayormente para la separación estilística se pueden incluso encontrar con facilidad en una sola vasija ychsma (Figura 1).

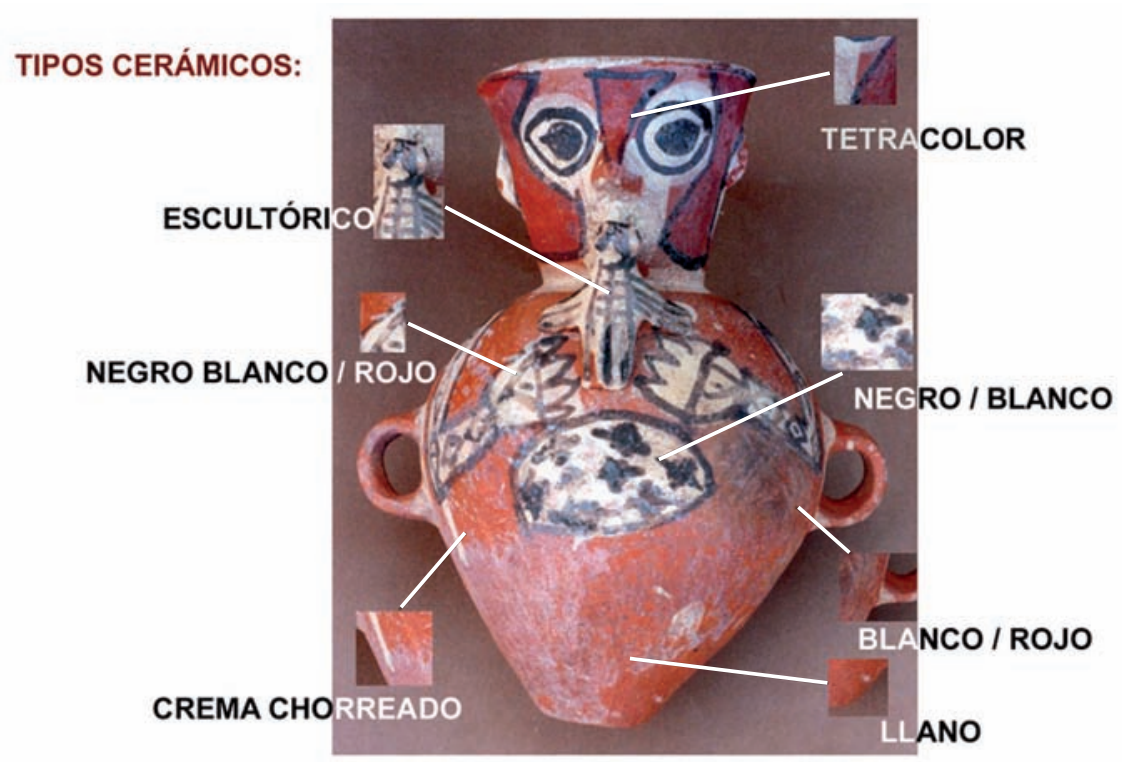

Figura 1. Ejemplo de los problemas derivados de la clasificación cerámica ychsma basada en algunas características decorativas. La imagen refleja la posibilidad de que varias "categorías" propuestas puedan incluso pertenecer a una sola vasija.

Figure 1. Example of the problems derived from the ychsma decorative-based pottery classification. The image reflects the possibility that several proposed "categories» may even belong to a single vessel.

Los criterios de clasificación que nosotros hemos venido usando para la definición del corpus cerámico Ychsma (Díaz y Vallejo, 2002; Vallejo 2004), apuntó necesariamente hacia un método tipológico basado en los principios de asociación. De manera similar, para la definición de la secuencia, nos hemos basado principalmente en la superposición física de los contextos arqueológicos, remitiéndonos a criterios de ordenamiento temporal, utilizando además la cronología relativa existente como criterio de secuencialidad. Finalmente, para la distribución geográfica, que requiere criterios de identificación precisos de los elementos cerámicos, es decir el método corológico, recurrimos al principio de recurrencia de los elementos cerámicos 
ychsma, presentes o reportados en los diversos sitios del área involucrada y de sus posibles colindancias con otras tradiciones estilísticas.

\section{El estilo YCHSMa. NUEVOS APORTES SOBRE LA CERÁMiCA YCHSMA}

La realización del coloquio «Arqueología de la Costa Central del Perú en los Periodos Tardíos» en el 2004, organizado por Peter Eeckhout de la Université Libre de Bruxelles (ULB) y la publicación de las ponencias presentadas en el Tome 33, No 3 del Bulletin de l'Institut Français d'Etudes Andines (Eeckhout 2004 [ed.]), marcan un hito sumamente importante en el estudio arqueológico de esta región. De hecho, varios de los estudios presentados, precisan y dan mayor claridad al estado de la situación sobre la investigación arqueológica concerniente a la sociedad Ychsma y, particularmente, apuntan a un mejor entendimiento de los elementos culturales pertenecientes a esta sociedad.

Sin embargo, como se desprende de estos estudios, la posibilidad de haber llegado a un entendimiento completo o siquiera general de la sociedad Ychsma aún está muy lejana. Una de las razones más determinantes en este aspecto, estriba en el hecho de que en realidad los estudios sistemáticos sobre esta sociedad están recién desarrollándose y muchos de sus resultados e investigaciones de campo aún se encuentran en proceso ${ }^{1}$. Con todo, creemos que la perspectiva a futuro es bastante satisfactoria en estos momentos, pues por fin se está abordando la cuestión de la sociedad Ychsma con la seriedad científica debida. Es importante, por ello, señalar para el caso de la cerámica, los estudios presentados tanto por Feltham y Eeckhout (2004), como el de Makowski y Vega Centeno (2004), los cuales, aunque toman el estudio de la cerámica desde perspectivas diferentes, presentan resultados específicos sobre la misma. También merecen mención los trabajos de Régulo Franco (2004) y Miguel Cornejo (2003) quienes elaboran cuadros culturales explicativos tomando como material de apoyo a la cerámica asociada.

Por otro lado, existen importantes trabajos de investigación relacionados con la problemática de la cerámica ychsma presentados en otras publicaciones, que igualmente constituyen aportes sustanciales al entendimiento y clasificación general de esta. Entre ellos, podemos mencionar a Ravines (2000), Guerrero (2004), Hudtwalker y Pinilla (2004) y Díaz y Vallejo (2005), los cuales ofrecen elementos importantes a la discusión a partir del estudio de diversos contextos arqueológicos asociados y en donde la cerámica está presente de manera relevante. 


\section{Sobre el Llamado Estilo "Puerto Viejo»}

No pocas confusiones han originado este término y su aplicación al estudio de la cerámica tardía de la región ychsma. Desde su primera identificación por Bonavia (1959), para el sitio del mismo nombre ubicado entre Chilca y Mala, estos elementos cerámicos han sido descritos como si se tratara de un conjunto diferente del corpus cerámico Ychsma. Este tipo de errores proviene del tiempo en el que aún se utilizaba el término «Huancho» para designar a la cerámica ychsma, cuando a esta solo se le consideraba como la "cerámica burda y llana» que existía en el valle bajo del Rímac (Iriarte 1960). Con los pocos estudios efectuados en sitios tardíos del bajo Rímac, el cuadro clasificatorio usado en ese entonces estaba separando a los componentes cerámicos del llamado estilo "Puerto Viejo" del estilo "Huancho", considerándose ambos como pertenecientes a dos grupos y etnias diferentes.

En realidad, cuando los estudios arqueológicos se han desarrollado con mayor envergadura en el bajo Rímac, en sitios como Armatambo, La Rinconada y Huaquerones (Puruchuco) por ejemplo, se ha visto con claridad que los criterios clasificatorios usados inicialmente para la cerámica tardía de esta región estaban muy limitados a solo pocos fragmentos diagnósticos, sesgando por ello los resultados de una seriación cerámica y mostrando un cuadro arqueológico irreal. La aparición en los sitios indicados de grandes grupos contextuales cerrados, como son mayormente los contextos funerarios, han permitido apreciar que lo que se venía considerando como un estilo diferente, era simplemente parte de las técnicas decorativas de un grupo cerámico mucho más complejo y rico en elementos que las simples características del llamado estilo Huancho. Bazán del Campo (1990) en su trabajo inicial sobre la cerámica ychsma, apunta correctamente sobre el error incurrido en las clasificaciones anteriores, incorporando aquellos tipos cerámicos como el famoso cara-gollete, que era considerado antes como el elemento más diagnóstico del estilo Puerto Viejo, en el grupo Ychsma.

Aunque estas apreciaciones pudieran parecer una simple formalidad en el uso de los términos, sus implicancias arqueológicas son muy importantes, pues es recién a partir de ellas que existe una herramienta arqueológica concreta para poder considerar a los valles bajos del Rímac y del Lurín como pertenecientes a un mismo grupo cultural. Si bien la etnohistoria, a partir de los trabajos de Rostworowski (1972, 1978), ya señalaba enfáticamente este aspecto, el estudio de la cerámica asociada y su correcta clasificación han hecho que exista además la evidencia material para corroborar dicha afirmación etnohistórica. 
Un trabajo anterior realizado por nosotros (Vallejo 2004), retoma el estudio de la cerámica tardía en esta región, incorporando definitivamente los componentes del llamado estilo Puerto Viejo en el estilo Ychsma y además intenta ordenarlos de acuerdo a un criterio de seriación y secuencialidad cerámica. Es claro, de acuerdo con este estudio, que los componentes del llamado estilo Puerto Viejo, son en realidad parte de las técnicas decorativas de la cerámica ychsma, presente en determinados tipos cerámicos (Figura 2). La recurrencia de estos tipos cerámicos en asociación directa de los demás componentes y tipos cerámicos ychsma, es harto evidente y documentada en los diversos trabajos de investigación realizados, no solo en los sitios mencionados del bajo Rímac, sino también en el bajo Lurín, con los sitios de Las Palmas (Paredes y Ramos 1994), Pueblo Viejo (Makowski y Vega Centeno 2004) y Pachacamac (Franco 1998, 2004; Feltham y Eeckhout 2004). Aun en el cercano valle bajo del Chilca (Engel 1984), la presencia de este tipo de material es notoria y relevante, guardando estrecha similitud con la hallada en los valles bajos del Rímac y Lurín.

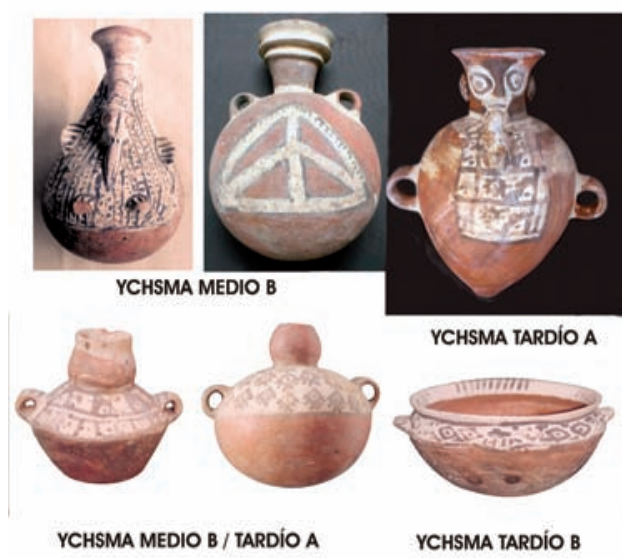

Figura 2. Tipos cerámicos ychsma que incorporan la decoración pictórica en las fases Medio B, Tardio A y Tardio B, halladas en Armatambo. Obsérvese que varios de estos elementos decorativos son clasificados por otros autores como pertenecientes al "estilo Puerto Viejo».

Figure 2. Ychsma ceramic types incorporating pictoric decoration in Medio B, Tardio A and Tardio B phases found in Armatambo. Notice that several of these decorative elements are classified as belonging to «estilo Puerto Viejo» by other authors.

Es extrańo, por ello, que aún algunos investigadores persistan en estas aparentes divisiones estilísticas (Makowski y Vega Centeno 2004), incorporando o sugiriendo en sus planteamientos la idea de prestaciones o de 
traslado de piezas cerámicas desde la zona de Mala o Chilca, lugar de donde se indica que provendría el estilo Puerto Viejo, hacia la zona del bajo Lurín o del bajo Rímac (Ángeles 2003; Ángeles y Pozzi-Escot 2004; Tantaleán y Pinedo 2004). Quizás debería tenerse presente que, cuando Bonavia (1959) realizó dicha clasificación, la muestra se componía casi exclusivamente de fragmentos decorados, sesgando de manera importante la muestra comparativa. Definitivamente, en las propias investigaciones arqueológicas, es usual que muchos investigadores asuman de hecho una posición localista con respecto al material identificado, creyendo que el sitio o el valle en estudio es necesariamente el origen del mismo, como se aprecia en los planteamientos de Ángeles y Pozzi-Escot (2004: 881-882) o de Tantaleán y Pinedo (2004) para los valles de Asia y Mala respectivamente. Lo más seguro, es que en cada uno de los valles señalados se esté fabricando cerámica local del estilo ychsma y por ello, estén presentes en cada una de estas piezas cerámicas algunas características particulares y locales, aun perteneciendo en general a este mismo estilo (Ángeles 2003: 19; Ángeles y Pozzi-Escot 2004: Fig. 20 derecha). Por otro lado, es evidente que la cerámica tardía en los valles de Mala y Asia todavía está en proceso de identificación, así que no sería nada raro que en ese proceso existan estilos propios en cada uno de ellos.

Como nuevamente recalcamos, las asociaciones y contextos arqueológicos donde el material llamado «Puerto Viejo» está presente en los valles del Rímac y del Lurín, son numerosos (Bueno 1983: 26, Fig b; Hyslop y Mujica 1992: Fig. 20; Isla 1995: Fig. 6 d; Díaz y Vallejo 2003b: Fig. 3, 2005: Figs. 14, 17; Franco 2004: Figs 36.2, 37, 38; Feltham y Eeckhout 2004: Figs. 14, 17, 33; Makowski y Vega Centeno 2004: Fig. 7; Vallejo 2004: Figs 11b, 11c, 13c, 13d, 14b, 15a, 16a, 17, 20k, 21b, 21c), y comprenden no solo los contextos funerarios (Díaz 2004; Díaz y Vallejo 2005), sino diversos contextos como los basurales, los "pagos», etc. Las características propias de este tipo de cerámica, donde la decoración pictórica es su principal elemento de identificación, han establecido que esta se encuentre solo en determinados tipos cerámicos, como algunos cuencos, botellas y especialmente en los conocidos cara-golletes (Figura 3), por lo que el criterio funcional en dicha cerámica está marcadamente presente y por tanto, su presencia corresponda también con determinados contextos. Por esta razón, su existencia en los contextos funerarios es resaltante, en comparación con estratos o contextos de origen doméstico o en el relleno de estructuras. Aquellos investigadores que hayan trabajado con contextos y material cerámico tardío o ychsma en estos valles, comprenderán fácilmente que la presencia de material decorado pictóricamente es mucho menor al material no decorado pictóricamente, por lo que 
la escasa presencia del material «Puerto Viejo» en algunos contextos o sitios se vuelve aun más notoria.

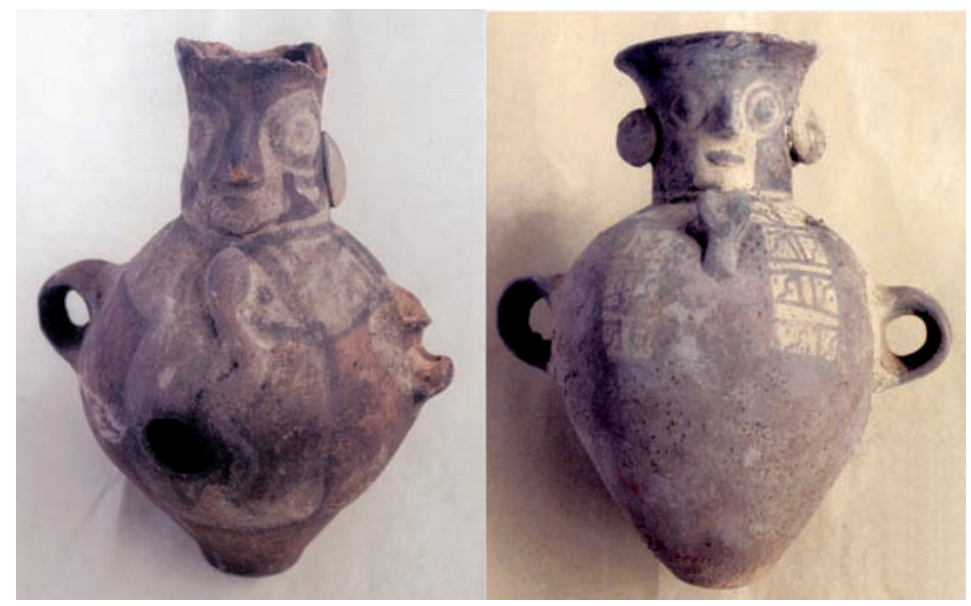

Figura 3. Vasijas escultóricas del tipo "caragollete" provenientes de contextos funerarios hallados en Armatambo (Diaz 2004).

Figure 3. "Caragollete" type sculpted vessels proceeding from funerary contexts found in Armatambo (Diaz 2004).

Por otro lado, como lo hemos observado en el estudio anteriormente señalado (Vallejo 2004), la presencia de material decorado para la cerámica ychsma, en los tipos conocidos como «estilo Puerto Viejo», solo comienzan a aparecer hacia la época Media, específicamente en la fase Ychsma Medio B, popularizándose hacia la siguiente fase Ychsma Tardío A, ambas fases de cronología preincaica. Durante la vigencia del imperio incaico, es decir en la fase Ychsma Tardío B, la decoración del tipo llamado Puerto Viejo, continúa realizándose, lo mismo que la producción de los tipos cerámicos cara-gollete, y aunque presentan algunas nuevas características, solo son una continuidad estilística de las fases precedentes o también presentan influencias originadas en la propia dinámica de la producción cerámica durante el imperio incaico.

En conclusión, el llamado "estilo Puerto Viejo» solo correspondería a varias formas decoradas pictóricamente del estilo Ychsma; y el que es considerado su tipo cerámico principal como son las formas cara-golletes, es en realidad una de las formas clásicas o tipo del estilo Ychsma, con gran recurrencia en los sitios ychsma de los valles bajos del Rímac y del Lurín, así como en el cercano valle bajo del Chilca. Otras formas típicas del llamado 
estilo Puerto Viejo, como los cuencos carenados y algunas botellas pequeñas, tienen las mismas características de pertenencia estilística con respecto al grupo Ychsma.

\section{CRITERIOS TÉCNICOS DE CLASIFICACIÓN PARA LA CERÁMICA YCHSMA.}

\section{ALGUNAS DE LAS CLASIFICACIONES ARQUEOLÓGICAS ANTERIORES}

Un intento inicial de nosotros por establecer la distribución geográfica del estilo ychsma y su secuencia tuvo que basarse necesariamente en los trabajos de campo desarrollados en lo que podría considerarse su área nuclear y sus áreas periféricas. Dado que las investigaciones arqueológicas en el valle de Lima han sido por lo general bastante limitadas, fue necesario revisar puntualmente los trabajos realizados en el valle próximo de Lurín principalmente aquellos desarrollados en el santuario de Pachacamac, así como también áreas vecinas como Chilca (Engel 1984), a fin de intentar definir el estilo cerámico local presente en esta región durante el periodo Intermedio Tardío.

Entre los primeros trabajos arqueológicos realizados, merece destacar el efectuado en Pachacamac por Strong y Corbett (1943), tomando básicamente los resultados que obtuvieron del corte practicado en el basural Este del Templo del Sol. La secuencia cerámica propuesta por ellos está basada en la existencia de varios grupos cronológica y estilísticamente diferentes, algunos tempranos como el estilo "Blanco sobre Rojo", muy relacionados según ellos con la cerámica hallada en Cerro Trinidad (Chancay), y el estilo "Pachacamac Interlocking» similar al hallado en Maranga (Lima). En estos trabajos notaron la ausencia de fragmentos del estilo, llamado en ese entonces, "Tiahuanacoide» (hoy correspondiente al estilo Huari). Para las fases tardías del sitio y a las que corresponde mayormente la conformación del basural excavado, establecieron dos grupos principales: el «Inca Asociado» y el «Inca Polícromo», desagregados a su vez en diferentes sub-tipos cerámicos cada uno. Un sub-grupo de difícil definición fue señalado como «Punteado e Inciso». Del análisis de las formas y tipos presentados para el "Inca Asociado», es claro para nosotros que la mayoría del material presentado corresponde al período Inca (Ychsma Tardío B), con ausencias notables de formas correspondientes al estilo Ychsma Temprano y Medio, salvo un pequeño fragmento del tipo "Punteado en Zona» (Strong y Corbett 1943: Fig. 19 - i).

Hacia finales de la década de 1950, Bonavia (1959), presentó un estudio sobre material cerámico recuperado en la zona de Puerto Viejo (Chilca) en una recolección de superficie. De los resultados de este estudio se definie- 
ron dos tipos principales: «Negro sobre Blanco» $\mathrm{y}$ "Cara gollete». El primer grupo corresponde a vasijas con decoración exterior de motivos estilizados (principalmente peces) delineados en color negro sobre la superficie tratada en color blanco (en realidad no se trata de color blanco, sino de un crema que en muchos casos está más cercano del amarillo). El segundo grupo es definido a partir de cántaros, particularmente tratados con una decoración antropomorfa en el gollete mismo de la vasija; esta consiste en la representación del rostro de un personaje en relieve y con trazos delineados en pintura negra, sobre fondos blancos y rojos. Aunque la muestra consistió mayormente de fragmentería, es de resaltar el hecho de que por primera vez son definidos en la literatura arqueológica tipos cerámicos de tradición netamente local con ausencia clara de formas o tipos Inca, de tal manera que estos fueron catalogados desde allí, y en diversos estudios posteriores como el estilo «Puerto Viejo».

\section{Fases e Interfases Cerámicas}

Algunos investigadores conciben la idea de que los cambios cronológicos en una secuencia cerámica corresponden obligatoriamente a cambios radicales en las tradiciones cerámicas, al punto de pensar en grupos cerámicos muy bien delimitados contextualmente por fases. En realidad, en los contextos arqueológicos, los cambios cerámicos aparecen y se suceden de forma gradual y es común encontrar elementos de diferentes fases en un mismo contexto. Si bien, desde un punto de vista formal, al querer precisar el aspecto cultural, nos inclinamos a hablar de grandes cambios o transformaciones de un estilo o tradición cerámica a otra, la propia dinámica social ha conducido a que un grupo humano asimile y reproduzca gradualmente estos cambios. Por ello, es preferible hablar de «formas tipo» o de «íconos tipo", para indicar a aquellos elementos cerámicos característicos de tal o cual fase, y que, por lo general, deben estar ausentes en las siguientes o anteriores fases, según sea el caso. Los cambios o mutaciones en las tradiciones cerámicas, pocas veces alcanzan a producirse en todo el corpus cerámico que utiliza una determinada sociedad y más bien afectan solo algunos elementos socialmente más representativos o funcionalmente más dinámicos.

Estos elementos deben ser tenidos muy presentes por los arqueólogos, cuando analizan determinados contextos arqueológicos que se encuentran objetivamente en el periodo de interfase. Dependiendo de la gradualidad de los cambios, los contextos arqueológicos de interfase, incluso pueden llegar a ser más numerosos que los propios contextos que se asignan exclusivamente a una única fase cerámica. En muchos casos, la utilización del 
concepto de «fase» por los arqueólogos, debe ser tomado como una herramienta de ordenamiento secuencial basada en determinados indicadores a fin de organizar el material en una posición de cronología relativa. A veces, este ordenamiento basado en cambios específicos en la tradición cerámica, puede correlacionarse con importantes cambios culturales que, además, se evidencian en otros órdenes del comportamiento social como la arquitectura, el patrón funerario, etc.

Este esquema parte de un principio básico utilizado en la arqueología, donde el elemento más tardío es el que asigna la datación definitiva del contexto. Por ejemplo, es común en varios contextos ychsma, hallar un conjunto cerámico con formas y tipos asignables a la fase Ychsma Tardío A (fase previa a la ocupación inca), pero que puede presentar uno o dos elementos de cerámica inca del estilo cuzqueño. Aunque proporcionalmente, los tipos cerámicos existentes son en su mayoría correspondientes a la fase previa a los incas, el contexto se asocia directamente con el periodo inca. Esto por supuesto, tratándose de contextos cerrados, y en donde los problemas de intrusión pueden ser descartados. La explicación de este hecho reside en que muchas de las formas y tipos cerámicos anteriores al periodo Inca continúan produciéndose al interior de la sociedad Ychsma, y los cambios que se producen en la cerámica local, luego de la ocupación incaica, se dan de manera gradual e inicialmente se expresan con pequeñas variaciones. Aun cuando este tipo de ejemplo es claramente evidente, la situación parece más difícil de entender cuando no necesariamente aparecen elementos cerámicos fácilmente reconocibles como aquellos pertenecientes al estilo Inca Cuzqueño, sino formas llamadas "híbridas" o formas locales influenciadas por el estilo Inca u otros estilos foráneos que interactúan en aquel periodo y, especialmente, cuando los elementos cerámicos son pertenecientes enteramente al estilo Ychsma, pero que solo aparecen en la época inca².

Solamente el cruce de información contextualmente válida y la recurrencia de determinados tipos cerámicos en asociación con los especimenes «marcadores», pueden crear cuadros cada vez mayores de grupos cerámicos, los cuales son definidos y ordenados en fases. El criterio usado en este caso, para la definición de fases cerámicas es puramente arqueológico, pues la cerámica ychsma, a diferencia de otras, es poco permeable a crear líneas continuas y secuenciales en base a algún diseño iconográfico específico, como cuando se aprecia la evolución de un determinado "icono" a lo largo del tiempo. Este tipo de ordenamiento secuencial, basado en la evolución iconográfica de determinados diseńos fue, de hecho, utilizado para el ordenamiento de las fases cerámicas Nazca y Wari (Menzel 1968), respectivamente. 
El ordenamiento en fases de la cerámica ychsma (Vallejo 2004) obedeció, por ello, a criterios exclusivamente arqueológicos, basándose especialmente en la presencia, recurrencia, asociación y superposición de los grupos cerámicos hallados en contextos cerrados. Bajo este aspecto, fue fundamental el uso de contextos funerarios, para la distinción y segregamiento de los grupos cerámicos que se ordenaron por fases dentro de una secuencia lo más objetiva posible. Es importante precisar que cada fase cerámica representa únicamente una parte del universo cerámico, y aunque se intente comprender todas las formas y tipos cerámicos involucrados en cada periodo, en términos prácticos solo se pueden identificar aquellas formas y tipos cerámicos susceptibles de ser aislados, tanto de los elementos cerámicos antecedentes, como de los precedentes ${ }^{3}$.

\section{TERRITORIO Y ETNICIDAD}

\section{El Territorio Ychsma: El Área Nuclear y las Áreas Periféricas}

Desde las primeras definiciones etnohistóricas dadas por María Rostworowski (1972) para la sociedad Ychsma a comienzos de la década de 1970, se ha especulado bastante sobre las características culturales y étnicas de esta sociedad, como también sobre su verdadera extensión territorial. Definitivamente, siendo las referencias documentales de la Colonia las que mayormente se han usado para este fin, es claro que muchos elementos concernientes quedan en el rango de lo hipotético para fines arqueológicos. Se suma el hecho de que estas fuentes coloniales lamentablemente no precisan estos aspectos de la sociedad Ychsma con la claridad debida, infiriéndose en el mejor de los casos solo algunos aspectos.

Aun en muchos casos, las descripciones coloniales para la región se refieren exclusivamente a la organización existente durante el periodo Inca, quedando apenas indicadas o mencionadas pocas referencias muy sueltas sobre la organización social anterior a los incas (Duviols 1967; Santillán 1968 [1563]), correspondiente con el periodo Intermedio Tardío y que venimos llamando también como periodo Ychsma. Dado que varios de los trabajos posteriores publicados por Rostworowski $(1972,1978)$ que utilizan documentos coloniales de archivo, apuntan a una suerte de unidad étnica y política entre los valles bajos de Lurín y del Rímac, parece muy probable que esta región sea efectivamente el área nuclear de la sociedad o cultura Ychsma (Cornejo 2000; Díaz y Vallejo 2003a, 2003b). Otras áreas periféricas al entorno de esta región básica, como sería el área de los valles medios (en especial la región llamada chaupiyunga), así como también el área del valle 
bajo del Chilca, parecen corresponder al resultado de influencias culturales y quizás expansivas de la sociedad Ychsma, especialmente ocurridas hacia finales del periodo Intermedio Tardío y especialmente durante el periodo incaico.

\section{ELEMENTOS ADICIONALES SOBRE LA SECUENCIA CERÁMICA YCHSMA}

\section{Los Finales del Horizonte Medio: la Época 4}

Cuando iniciamos la tarea de organizar secuencialmente al material cerámico ychsma, nos encontramos con grandes dificultades, en especial al tratar de definir, de acuerdo a la información existente, al material cerámico perteneciente a los dos horizontes cronológicos que enmarcan el Periodo Intermedio Tardío. Salvo el material con iconografía fácilmente reconocible, como la wari e inca respectivamente, el resto de material cerámico asociado perteneciente a estos periodos era en su mayoría desconocido o poco reportado.

Si nos remitimos exclusivamente a la cerámica de finales del Horizonte Medio (Época 4), esta apenas es esbozada en sus características más básicas en el estudio de Menzel (1968). Se suma a ello, que el material debidamente reportado para los valles del Rímac y del Lurín es muy escaso, y aun, las colecciones cerámicas existentes sobre esta época en particular son igualmente limitadas. Tanto en Pachacamac como en Huallamarca, se conservan varios especímenes de este periodo, pero es necesario definir las características formales de ambos grupos.

En Pachacamac, por ejemplo, material conocido de este periodo parece provenir de un antiguo cementerio ubicado en el sector llamado de «Puente Lurín», donde hacia las décadas de 1960 y 1970 se recuperaron diversos especímenes cerámicos. En los depósitos del Museo de Sitio de Pachacamac, existen por ello, varias piezas que guardan estrecha relación con el periodo final del Horizonte Medio. Este periodo, que Menzel (1968) llamó como Época 4, parece configurarse como una época de abandono casi completo de los cánones estilísticos wari, que predominaban en las épocas 2 y 3 anteriores (Figuras 4, 5). Tanto los acabados como los diseños mismos de la Época 4, reproducen elementos apenas remanentes de las épocas anteriores. Los acabados mates, aunque todavía polícromos, y los diseños restringidos a algunos elementos geométricos repetitivos, son característicos de este periodo, así como el aumento de formas escultóricas modeladas (Figura 6). Las afinidades estilísticas con el estilo Huaura, imperante en la región del 
Norte Chico e incluso en Ancón (Willey 1943: Plate 1), son evidentes y notorias, tal como aparece con ligeras variantes en algunos especímenes de Huallamarca (Guerrero 2004: Foto 7). Por ello, nos parece que los hallazgos del Templo Viejo (Franco 1993, 2004; Franco y Paredes 2001) se encuentran mucho más relacionados con la Época 4 que con las precedentes, precisamente porque son coincidentes con las características formales de la cerámica de finales del Horizonte Medio que se conocen.

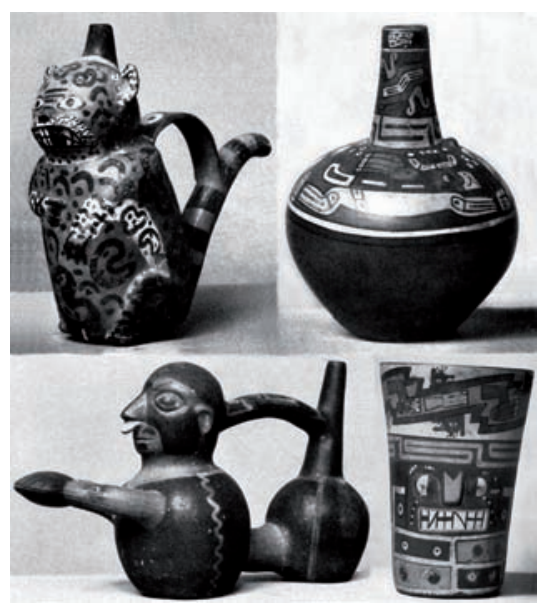

Figura 4. Cerámica de la época 2 del Horizonte Medio hallada en Pachacamac (Schmidt 1929). Obsérvese los elementos de diseño y de acabado muy formalizados con los cánones estilísticos wari.

Figure 4. Middle Horizon Epoch 2 pottery found in Pachacamac (Schmidt 1929). Notice highly formal design and termination elements with Wari stylistic canons.

Aunque la Época 4, por la declinación en las técnicas cerámicas, pareciera también una época de declinación cultural, en realidad constituye un periodo de surgimiento de los elementos que caracterizaran culturalmente a la sociedad Ychsma. Uno de estos elementos principales, de hecho, estuvo constituido por el ídolo de Pachacamac al cual se le rindió culto, y objetivamente, fue el elemento central de su religión.

Las afinidades de los motivos iconográficos presentes en el ídolo con las fases estilísticas de finales del Horizonte Medio e inicios del estilo Ychsma, son mayores cuando se ven en conjunto las representaciones talladas del ídolo, ya muy distantes de los cánones estilísticos wari de la Época 2, y más emparentados con representaciones en cerámica que utilizan diseños impresos a partir de moldes. En la Época 3 esta técnica decorativa está especialmente presente en varios valles norteńos como Casma y Huarmey con diseños formalizados y muy recurrentes, y además con un tratamiento más 
geométrico. Pero es mayormente a finales del Horizonte Medio (Época 4), que las vasijas que utilizan esta técnica en el estilo Huaura, adoptan diseños más curvilíneos, con una representación simbólica aun más variada y rica en elementos que asemejan escenas en movimiento. Este tipo de representaciones se encuentran con frecuencia muy presentes en los valles bajos de Huaura, Pativilca y Paramonga (Carrión Cachot 1959). En un anterior trabajo (Vallejo 1988), habíamos notado las semejanzas formales entre los motivos del ídolo de Pachacamac y las representaciones simbólicas de la zona Huaura-Pativilca, ilustrados por Carrión Cachot, especialmente en la llamada «escena celestial» y la representación de la "pareja divina», muy ligados con los mitos de creación y fertilidad que relacionan las divinidades de Vichama y Pachacamac consignados por el agustino Calancha (1974).

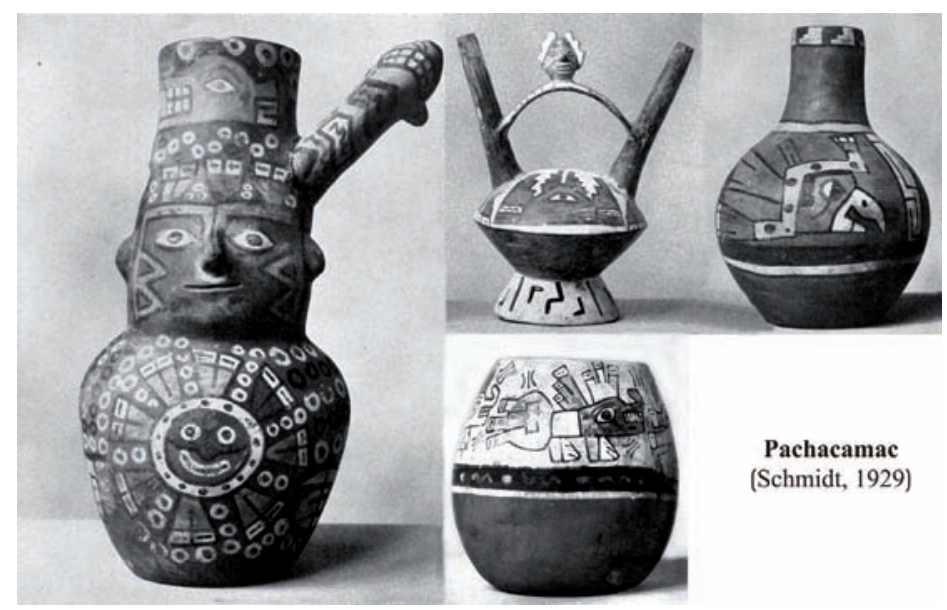

Figura 5. Vasijas de la época 3 del Horizonte Medio provenientes de Pachacamac (Schmidt 1929). Algunos diseños provenientes de la época 2 aún se continúan reproduciendo, aunque la riqueza temática se ve restringida a pocos elementos por vasija.

Figure 5. Middle Horizon Epoch 3 vessels proceeding from Pachacamac (Schmidt 1929).

Some epoch 2 designs are still reproduced, although theme richness is limited to few elements per vessel. 


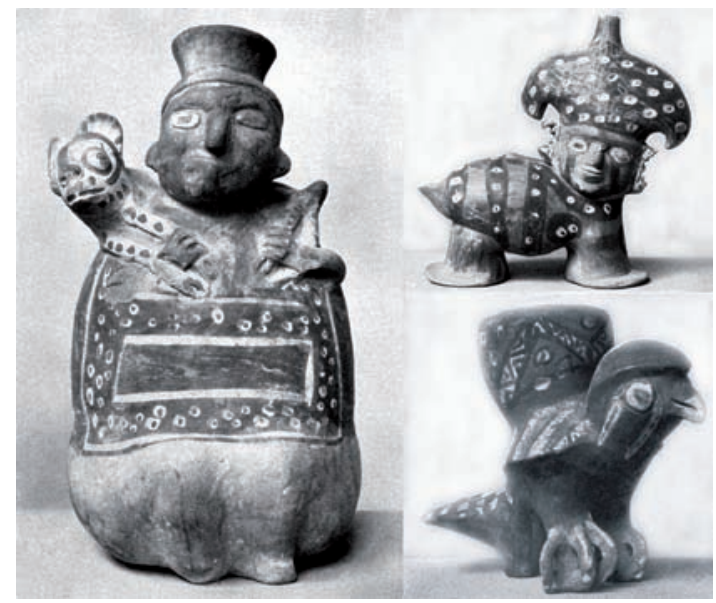

Figura 6. Pachacamac. Cerámica de la época 4 del Horizonte Medio (Schmidt 1929). Acabados mate o con poco pulimento caracterizan esta época. Los diseños pictóricos muchas veces se limitan a pequeños elementos decorativos como circulos y lineas paralelas o zigzagueantes.

Figure 6. Pachacamac. Middle Horizon Epoch 4 pottery (Schmidt 1929). Mate or little polish terminations characterize this epoch. Picture designs are often limited to small decorative elements as circles and parallel or zigzag lines.

Si nos detenemos a analizar las representaciones impresas en la cerámica, vemos que en general estas parecen describir escenas míticas, donde generalmente figura de manera recurrente un personaje central, muy probablemente derivado del dios de los báculos wari, el cual aparece con los brazos abiertos y con una serie de elementos iconográficos y seres que lo rodean. Además de seres o personajes complementarios y con atributos que podríamos considerar míticos, como felinos o cánidos con apéndices que sobresalen del cuerpo, aparecen otros seres adicionales diseñados con un tratamiento naturalista, especialmente en las representaciones de peces y aves. Una de estas escenas reproducidas por Dulanto (2001: Fig. 83), ejemplifica este modelo de diseño iconográfico, donde es posible ver incluso ciertas semejanzas en el tratamiento de los seres naturalistas, peces y aves por ejemplo, con las representaciones existentes en el lado B de la Puerta de Pachacamac (Vallejo 2005).

Tanto en la idea misma de la representación de las deidades, como especialmente en la serie de elementos adicionales o complementarios que se añaden a la deidad o deidades principales, las semejanzas estilísticas y conceptuales de diseńo son bastante marcadas entre todas estas representaciones aludidas, hecho que también encuentra bastante coincidencia con las afini- 
dades estilísticas a nivel de secuencia cerámica. Es claro una vez más, que las regiones huaura e ychsma estuvieron muy articuladas en un momento determinado, especialmente hacia la Época 4 del Horizonte Medio, época de mayor prestigio y difusión del estilo Huaura (Figura 7). Si la evidencia arqueológica a partir del estudio de la cerámica es correcta, la zona ychsma fue fuertemente influenciada por la zona huaura en la Época 4, al punto de que quizás hubiera incluso una suerte de dependencia o sujeción política hacia Huaura (Vallejo 2004). De ser cierta esta hipótesis, la religión debió también estar en cierta manera condicionada por estos factores y reflejar una primacía o quizás una competencia entre ambas zonas.

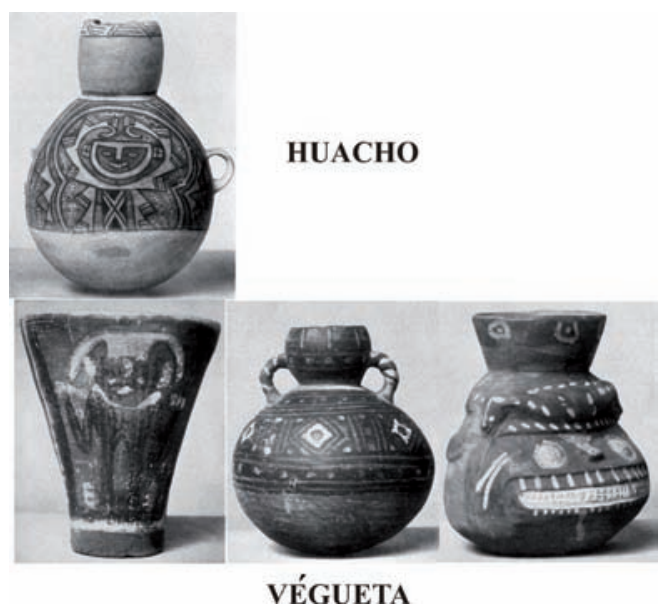

Figura 7. Cerámica del estilo Huaura procedente de Huacho y Végueta (Schmidt 1929). Tanto los elementos de diseño como las formas cerámicas utilizadas, caracterizan un estilo muy definido y particular.

Figure 7. Huaura style pottery proceeding from Huacho and Végueta (Schmidt 1929). Both design elements and used ceramic forms characterize a well-defined and particular style.

Los mitos recogidos por el Padre Calancha (1974), sobre la lucha de Vichama, un dios de la zona de Huaura (Végueta - Huacho), y Pachacamac, un dios de la zona ychsma, pueden ser una muestra de la rivalidad que surgió en un momento entre ambos territorios étnicos y que marcarían el punto de distanciamiento e independencia política y estilística de la zona ychsma con respecto a la de Huaura, conservadas en la mitología de los indígenas de Végueta y Huaura, como reminiscencias de conflictos anteriores. Precisamente, en el tejido publicado por Schmidt (1929) proveniente de Pachacamac (Figura 8), las escenas de guerra y enfrentamiento entre varios grupos de personajes evidencian una suerte de periodo de extrema belicosidad, prácti- 
camente ausente en todas las representaciones estilísticas ychsma de las fases Media y Tardía. Escenas similares son también visibles en el textil publicado por Ubbelohde-Doering (1952: 81). Las fases Ychsma Temprano (A y B) podrían tratarse más bien de un periodo de independencia y consolidación del territorio étnico ychsma en torno al culto totémico de la antigua deidad conocida como Ychsma o Pachacamac. La ausencia de fechados radiocarbónicos de la puerta y del ídolo de Pachacamac, evitan que puedan datarse definitivamente estos eventos, pero tomando al menos comparativamente otros registros absolutos referenciales, se puede establecer este periodo entre el 900 y el 1000 d.C., tiempo en que se estaría produciendo el final de la Época 4 del Horizonte Medio e inicios del Periodo Intermedio Tardío en toda la costa central.

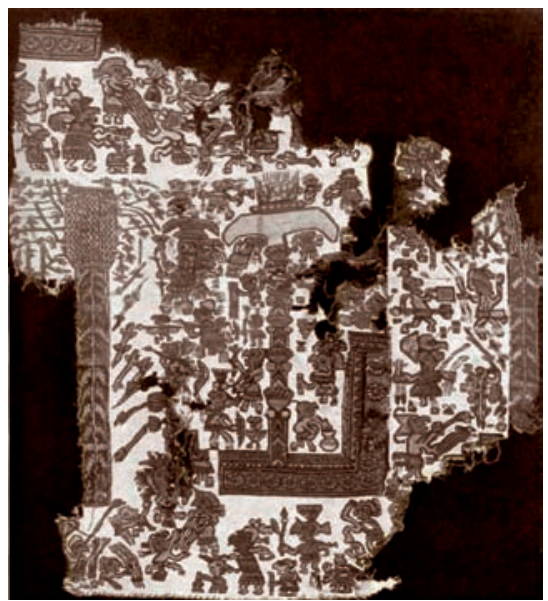

Figura 8. Textil decorado hallado en Pachacamac con representación compleja (Schmidt 1929). Los elementos de diseño encuentran paralelismos con las fases cerámicas Ychsma Temprano.

Figure 8. Decorated textile found in Pachacamac with a complex representation (Schmidt 1929). The design elements have similarities with Early Ychsma ceramic phases.

\section{La Época Ychsma Temprano}

El punto de diferenciación estilística y cronológica entre los finales de la Época 4 del Horizonte Medio y los comienzos del Periodo Intermedio Tardío (fase Ychsma A), aparecen hasta ahora poco claros, en especial lo referente a los tipos y formas cerámicas involucradas. Aunque tenemos nociones básicas sobre este periodo de cambio, es claro que resta mucho por definir. Los recientes trabajos arqueológicos, los cuales aún no están publicados, en el cementerio existente frente al Templo de Pachacamac realizados por la misión belga del Proyecto Ychsma dirigido por Peter Eeckhout y Carlos 
Farfán, y los más recientes del Pachacamac Archaeological Project, dirigidos por Izumi Shimada y Rafael Segura, de seguro brindaran información consistente al respecto.

Por el momento, es definitivamente el material perteneciente al sitio de Huallamarca en el valle bajo del Rímac, el fundamental para entender esta época, pues representa precisamente el periodo de cambio entre finales del Horizonte Medio e inicios del Periodo Intermedio Tardío. Los estudios de Casas y Dolorier (2004) sobre este material están en proceso, los cuales, sumados a los ya señalados de Pachacamac, podrían llenar el vacío que aún se tiene sobre este periodo. Recientemente Guerrero (2004: fotos 5, 6), ha publicado parte de este material, relacionándolo con el estilo Tricolor Geométrico definido en el valle de Chancay por Horkheimer (1970), aunque asignándolo cronológicamente al Horizonte Medio. Al respecto conviene tener presente, que no necesariamente la decoración polícroma o tricolor representa mecánicamente una pertenencia al Horizonte Medio, pues como hemos señalado anteriormente (Vallejo 2004), la fase Ychsma Temprano A incorpora en sus diseños este tipo de decoración polícroma, con al menos tres colores básicos: crema o blanco, rojo y negro, además de varias tonalidades que se derivan de ellos, como el plomo y el naranja. Aunque la mayoría de acabados son en mate, existen algunos especímenes pulidos, pero son proporcionalmente menores. Aparentemente, el proceso de diferenciación estilística, ocurrido entre finales del Horizonte Medio e inicios del Periodo Intermedio Tardío, tuvo un similar proceso en la región ychsma como en la de Chancay, al punto que existen algunas relaciones entre el estilo Tricolor Geométrico de Chancay (Horkheimer 1970: 366, Fig. a) con el Ychsma Temprano A (Figura 9), ambos pertenecientes a inicios del Periodo Intermedio Tardío (Tabla 1).

Siendo esta una etapa de fuertes cambios, aún queda por definir muchas de las pertenencias estilísticas que se observan en los contextos asignables a este periodo. Por ejemplo, muchas de las representaciones textiles Ychsma Temprano señaladas, parecieran guardar cierta relación estilística con elementos estilísticos Lambayeque, como cuando se representan las piernas en forma zigzagueante, lo mismo que ocurre con determinadas vasijas Ychsma Temprano (Uhle 1903) que muestran ligeros paralelismos con algunas vasijas sicán, en especial las comúnmente llamadas "huaco rey».

Quizás, el punto de mayor ruptura y de diferenciación con los periodos precedentes del Horizonte Medio, se dé durante la fase Ychsma Temprano $\mathrm{B}$, cuando se abandona casi completamente la decoración pictórica o esta 
queda apenas restringida al uso de dos colores, como el crema que se aplica sobre la superficie natural de las vasijas, o el negro que se aplica en algunos pequeños diseños (Guerrero 2004: Fotos 8, 9, 10, 11). Se ensayan otras formas decorativas más simples, como los bruñidos, la cocción reductora o la elevación y forma de los cuellos, por ejemplo. La aplicación de algunos apéndices pequeños, algunas superficies pulidas, y en general, el contorno de las vasijas de tipo compuesto, indican que estas técnicas ornamentalmente sustituyen a la ausencia general de decoración pictórica.

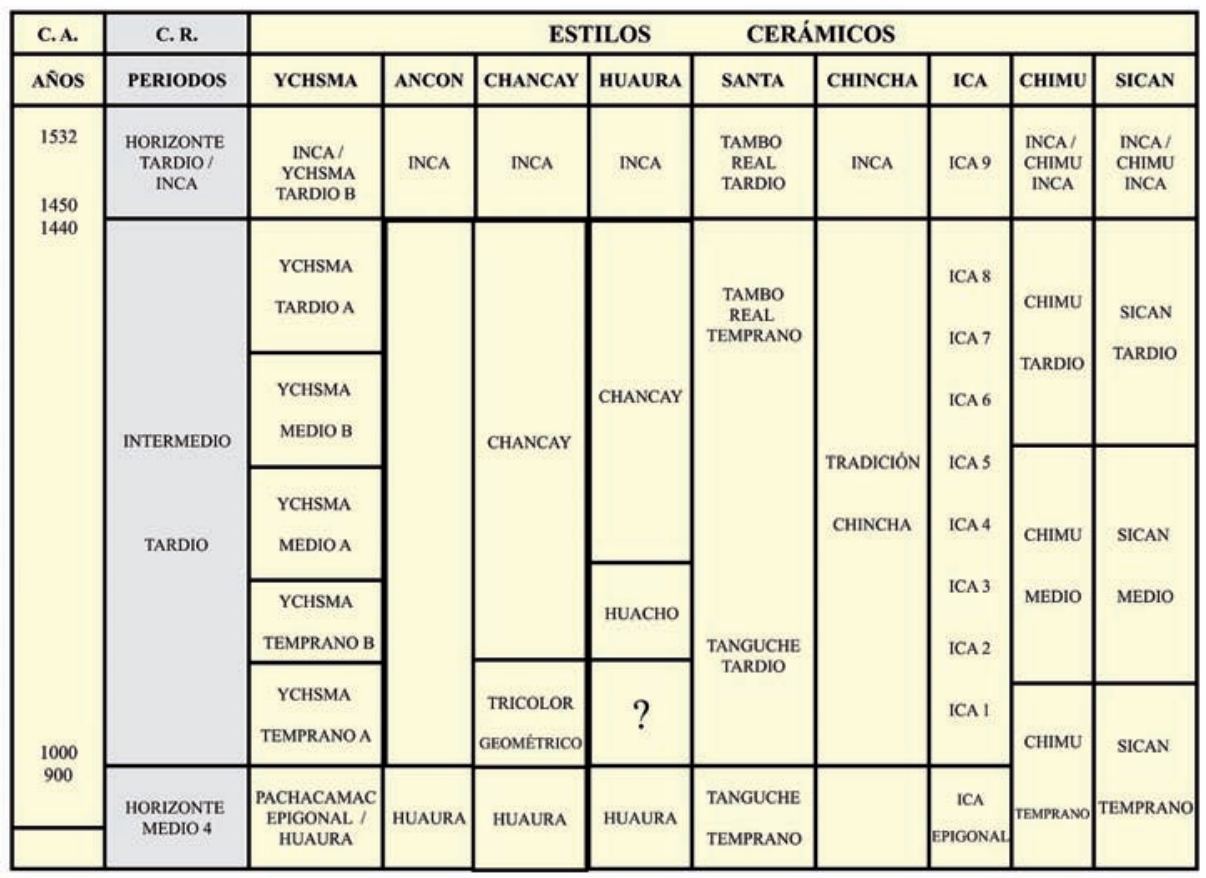

Tabla 1. Cuadro cronológico.

Table 1. Chronological table. 

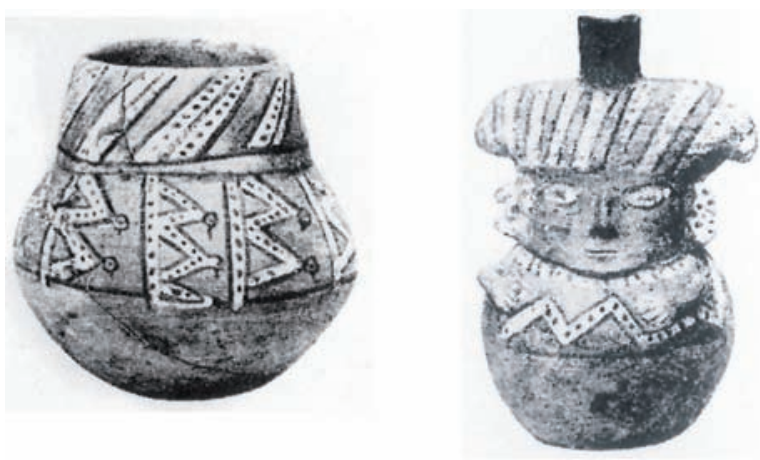

Pachacamac

(Unle, 1903)

Figura 9. Cerámica de la fase Ychsma Temprano A hallada por Uble (1903) en sus excavaciones del cementerio ubicado frente al Templo de Pachacamac.

Figure 9. Early A Ychsma phase ceramic found by Uhle (1903) during his excavations in the cemetery located in front of Pachacamac's temple.

¿Cuál pudo ser la causa de este cambio tan radical? Es difícil saberlo por la escasez de asociaciones específicas con este periodo, pero algunos indicios parecieran indicar una aislamiento de la región ychsma con respecto a las aledańas, quizás producto de cambios sociales al interior de la propia estructura política ychsma al desagregarse en pequeños curacazgos, presiones étnicas de grupos del entorno, o lo que parece también probable, una suerte de desertificación del medio, motivado por una escasez de lluvias en la sierra en un periodo relativamente prolongado, seguido de un periodo de grandes precipitaciones. Cualquiera de estos factores, o la combinación de algunos de ellos, pueden haber motivado los cambios radicales observados en la cerámica y que se reproducen de alguna manera en el patrón de ocupación de los valles bajos, mucho más disperso e intensivo que los periodos precedentes, pues aunque existan pocos reportes para esta fase, varios de los sitios ychsma parecieran originarse o crecer en este periodo, como el de Macattampu o Armatambo ${ }^{4}$ por ejemplo. Al parecer, durante esta fase es que se vuelven recurrentes los enterramientos de grandes cántaros o de tinajas, como los hallados en la cima del Templo Viejo en Pachacamac (Franco 1993: Foto 4; Franco 2004), si es que ello puede ser indicio de un culto al agua mucho más extensivo y popular que el existente en los periodos inmediatamente anteriores. 


\section{La Época Ychsma Medio}

Reflejo del anterior culto relacionado con el enterramiento o uso de grandes cántaros y tinajas, en la fase Ychsma Medio A, también se puede apreciar en la arquitectura «improntas» o perforaciones existentes en los pisos de varios espacios importantes, donde seguramente se encontraron antiguamente semienterradas este tipo de vasijas y en asociación directa con las actividades desarrolladas en estos mismos espacios. Ejemplos de este tipo de evidencias han sido halladas en Armatambo (Díaz 2004), La Rinconada (Díaz 2002) y en La Huaca San Borja (Rea 2001). En la Huaca San Borja, varios de los recintos y patios superiores se encuentran con perforaciones circulares de poca profundidad dispuestas en un patrón lineal; es evidente así que estos pisos contuvieron una serie de vasijas grandes.

La mayoría de las vasijas de la Fase A presentes en los contextos ychsma, no presentan ningún tipo de decoración pictórica, usándose preferentemente las superficies naturales. En algunos casos la decoración apenas se restringe al uso de toscas aplicaciones de color crema, a manera de líneas gruesas horizontales alrededor del cuello o pequeñas líneas del mismo color en los labios (Díaz y Vallejo 2005: Figs. 8A, 9A), líneas en color negro sobre fondo crema (Figura 10), o aquella que utiliza punteados e incisiones (Figura 11) (Franco 2004: Fig. 34; Shimada et al. 2004: Fig. 7).

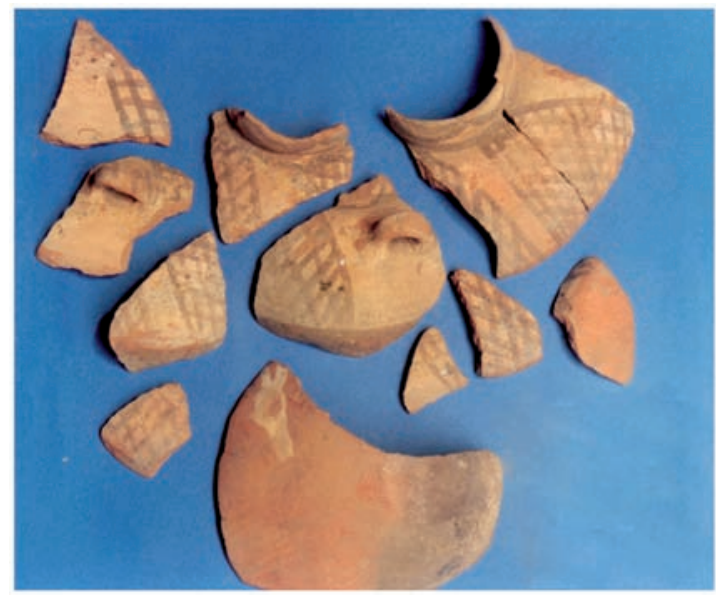

Figura 10. Vasija de la fase Ychsma Medio A (Díaz 1998).

Figure 10. Middle A Ychsma phase vessel (Díaz 1998).

Aunque la Fase A de esta época, iconográficamente es relativamente pobre, en la fase siguiente (Ychsma Medio B) comienzan a aparecer muchos de los diseños y motivos que caracterizarán al estilo Ychsma, en especial los basados en la decoración pictórica negro y crema que aparecerá en varias 
vasijas (Díaz y Vallejo 2005: Fig. 14), como las formas de pequeñas calabazas (Figura 12). De igual manera, las vasijas del tipo cara-gollete comienzan a ser algo frecuentes en los contextos ychsma, especialmente en los funerarios (Díaz y Vallejo 2005: Fig. 17) (Figura 13 a), como aquellas vasijas que incorporan pequeñas aplicaciones modeladas (Figura $13 \mathrm{~b}$ ). Con todo, el volumen de piezas sin ninguna o poca decoración pictórica es muy superior al de vasijas decoradas.

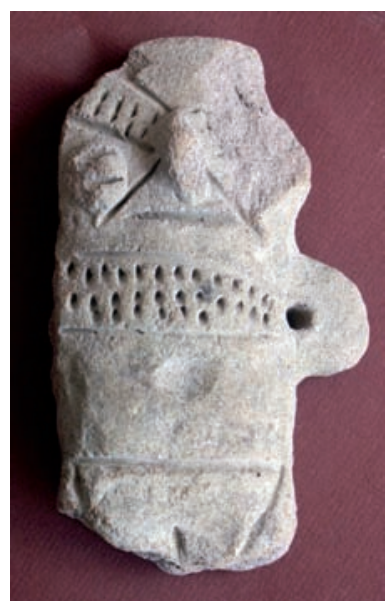

Figura 11. Figurina modelada de la fase Ychsma Medio A, con aplicaciones de punteado en zona e incisiones (Pachacamac).

Figure 11. Middle A Ychsma phase modeled figurine with pointed applications in the zone of incisions (Pachacamac).

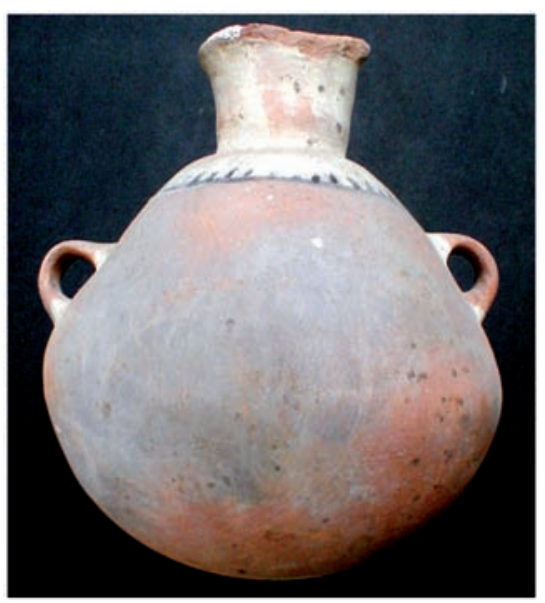

Figura 12. Vasija fitomorfa de la fase Ychsma Medio B que reproduce una calabaza (Armatambo).

Figure 12. Middle B Ychsma phase fitomorph vessel reproducing a pumpkin (Armatambo). 
Desde el punto de vista de la arquitectura, la época Ychsma Medio aparece aún con poca definición, debido al hecho de que todavía no se ha podido aislar convenientemente un edificio correspondiente con esta época. Sin embargo, en Armatambo (Díaz 2004) varios ejemplos de arquitectura de este periodo aparecen claros y suficientemente aislados de periodos posteriores. Tanto Mateo Salado, La Huaca Santa Catalina, la Huaca San Borja y Mangomarca, por citar algunos edificios ychsma del valle bajo del Rímac, parecen decididamente corresponder con esta época. Las características arquitectónicas de todos estos edificios se inclinan a crear grandes volúmenes en base a tapiales y rellenos sucesivos, a los cuales se les van sumando nuevas etapas constructivas que cubren las etapas anteriores, tanto con adosamientos sucesivos de tapiales como con nuevos rellenos estructurales (Tello 1999). Una característica importante en estos edificios, es que muchas veces los rellenos aparecen mayormente limpios o con poca presencia de material cerámico, dificultando los trabajos de análisis comparativo. En varios casos, los perfiles de estos edificios son de forma escalonada en base a plataformas superpuestas contenidas con gruesos muros de tapial (Bueno 1991), y no son raros los amurallamientos o la construcción de altos muros en tapial que rodean los asentamientos.

En Pachacamac, son pocas las estructuras que señaladamente se pueden asociar con esta época, pues muchos de los edificios actualmente visibles corresponden con la ocupación tardía del sitio. Muchas de estas estructuras se asocian con el uso de adobes alargados o de altura pequeña, que aparecen parcialmente cubiertos por las estructuras más tardías o que se encuentran muy deterioradas por exposición. Entre todas ellas, destaca notablemente una estructura existente en el lado oeste del sitio, la cual ha sido reportada por Díaz (2004) y que espacialmente se diferencia de las conocidas Pirámides con Rampa, las cuales solo parecen asociarse con la ocupación tardía del sitio (fase Ychsma Tardío A). 


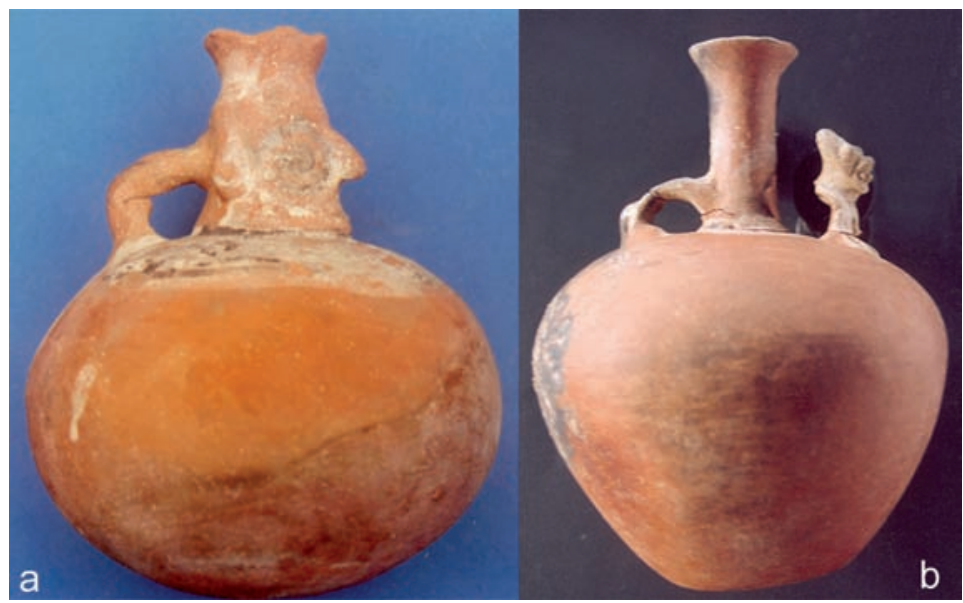

Figura 13. Botellas ychsma de la interfase Medio A y Medio B, procedentes de Armatambo (Diaz 1998, 2004).

Figure 13. Middle A and B Ychsma interphase bottles, proceeding from Armatambo (Diaz 1998, 2004).

La ocupación de parte de la banda derecha del Rímac, tan poco conocida arqueológicamente, parece quedar confirmada con las investigaciones de Ravines (2000) en el sitio de Canto Chico, que correspondió al grupo de Lurigancho. De acuerdo al material cerámico presentado para este sitio, es claro que gran parte del mismo corresponde a la época Ychsma Medio y Tardío A, por lo que Canto Chico se presenta como un caso de continuidad ocupacional sucesiva. En Las Palmas (Paredes y Ramos 1994) presentan un conjunto cerámico bastante similar al de Canto Chico, con evidencia también de continuidad ocupacional para una misma área. Si nos detenemos a analizar el material Ychsma Medio de Canto Chico, veremos notables semejanzas con material similar reportado para la banda izquierda del Rímac y para el valle de Lurín, como por ejemplo algunos tipos de ollas y tinajas (Ravines 2000: 140, Figuras 4, 5), y tinajas de cuello en T (Ravines 2000: $218,219,220,221,222)$. También en el caso de especímenes modelados como las figurinas (Ravines 2000: 260, Figs. 1,2) y las aplicaciones (Ravines 2000: 255), estas son coincidentes con las reportadas en Armatambo o en Pachacamac, entre otros sitios.

En las zonas de rinconadas del valle del Rímac, como aquella donde se ubica Cajamarquilla, aparece con alguna frecuencia material cerámico perteneciente a este periodo. Aunque no está todavía clara su relación con la arquitectura presente, es evidente, por los estudios de Joaquín Narváez (2006) en el sitio mismo de Cajamarquilla, que varias formas y tipos cerámicos ychsma son utilizados en este lugar. Definitivamente, el material ychsma que 
mayormente se presenta, como bien señala Narváez, se encuentra asociado con la fase Ychsma Medio A, aunque algunos especimenes todavía presentan claras reminiscencias con la fase anterior (Narváez 2006: Figs. 245, 248).

\section{La Época Ychsma Tardío}

La época Ychsma Tardío se diferencia notoriamente de las anteriores por su gran dinamismo, al punto de que el registro arqueológico y la mayoría de publicaciones que presentan material ychsma, lo hacen con material y contextos pertenecientes a esta época. $\mathrm{Al}$ igual que las épocas anteriores, esta etapa se encuentra subdividida en dos fases: A y B.

En la Fase A, la evolución del estilo a nivel cerámico presenta grandes cambios, especialmente en las características técnicas, aunque morfológicamente también se presentan varios cambios relevantes. Conjuntos cerámicos pertenecientes a esta fase, y al parecer aislados del material más tardío correspondiente con la fase B (periodo inca), han sido reportados en Canto Chico (Ravines 2000), Armatambo (Díaz 2004; Díaz y Vallejo 2005), Las Palmas (Paredes y Ramos 1994) y Pachacamac (Feltham y Eeckhout 2004), aunque evidentemente en muchos otros sitios ychsma el material correspondiente a esta fase está muy presente. Durante esta fase, no es rara la presencia de cerámica elaborada en ambiente reductor (Figura 14), la cual también se manifiesta en las otras fases ychsma pero en mucha menor proporción ${ }^{5}$.

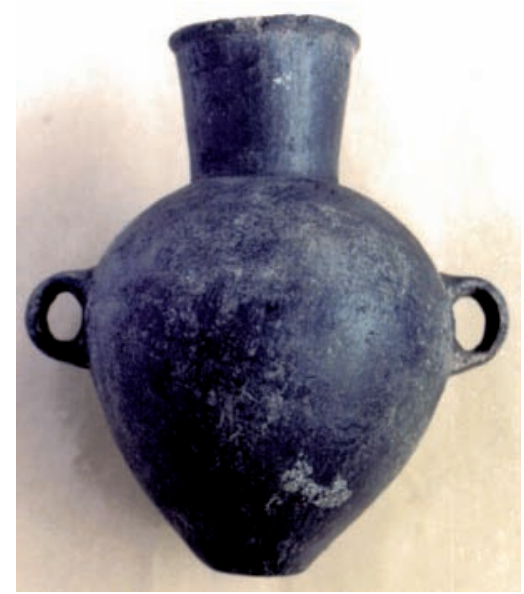

Figura 14. Vasija de la fase Ychsma Tardio A, procedente de un contexto funerario hallado en Armatambo (Díaz 2004).

Figure 14. Late Ychsma phase vessel, proceeding from a funerary context found in Armatambo (Díaz 2004). 
El reciente trabajo de Feltham y Eeckhout (2004) sobre la cerámica hallada en la Pirámide con Rampa III de Pachacamac, apunta a una mayor definición de esta fase y, en especial, a clarificar cuáles son las características morfológicas propias que la distinguen de los componentes cerámicos de la siguiente fase ychsma correspondiente con el periodo Inca. Este importante trabajo no deja dudas sobre la existencia de dos fases tardías para la cerámica ychsma, pues se ha contado con material proveniente de excavaciones arqueológicas y de asociaciones específicas en uno de los sitios principales de la sociedad Ychsma. El trabajo de Ravines (2000), en Canto Chico, aunque no logra distinguir las fases involucradas, sirve para visualizar muchas de las formas Ychsma Tardío A presentes en este sitio (Ravines 2000: 122, 124, $177,203,204,211,213)$.

En Pachacamac, es precisamente donde se ha encontrado la mayor concentración de Pirámides con Rampa y es en este mismo sitio donde se ha podido definir el modelo arquitectónico, a partir de la excavación de tres de ellas: las Pirámides con Rampa No 1, 2 y 3 (Jiménez Borja 1985; Paredes y Franco 1987; Paredes 1988; Eeckhout 1995, 1999; Franco 1998, 2004). Si analizamos el material cerámico presente en cada una de ellas asociado con su uso, resulta claro que todas ellas corresponden cronológicamente con las fases más tardías de la secuencia ychsma. $\mathrm{Al}$ parecer, el modelo arquitectónico de las Pirámides con Rampa en Pachacamac, encuentra su mayor difusión en la fase Ychsma Tardío A, coincidiendo quizás con un mayor dinamismo que la sociedad Ychsma presenta en aquel periodo.

Para la fase Ychsma Tardío B correspondiente con el periodo Inca, la concurrencia de diversos estilos cerámicos ha hecho dificultosa la asignación o pertenencia estilística de muchos de los especímenes involucrados en esta fase, por ser parte de un proceso mucho más complejo que suma diversos factores tecnológicos, funcionales y estilísticos en la producción cerámica. La complejidad de este periodo, se expresa en una serie de formas y tipos cerámicos que muchas veces escapan a los criterios formales que se tiene para clasificar determinado estilo, concurriendo muchas veces en una sola vasija varios elementos que recuerdan o se acercan a diversos estilos cerámicos (Figura 15). Por ello, las formas atípicas son muy comunes en este periodo. De alguna manera, las variantes en la cerámica y el surgimiento de nuevas formas o tipos cerámicos, deben ser correspondientes con la complejización social y los fuertes movimientos sociales que se encuentran al interior del imperio incaico. El traslado de grupos humanos completos, como son los famosos mitimaes, las redes de intercambio y tributación ampliamente difundidas y muy dinámicas, y especialmente los nuevos roles que el estado 
incaico establece en todos los órdenes sociales, hacen que la producción cerámica alcance niveles nuevos, tanto en volumen como en variantes morfológicas y tecnológicas.

Los problemas también residen en la propia clasificación del material de estilo Inca Cuzqueño, el cual recibe a veces libremente diversas denominaciones, como las conocidas Inca Imperial e Inca Provincial, tal como lo ha señalado ya anteriormente Meyers (1975). Nosotros hemos hecho al menos dos grandes distinciones, la que corresponde al estilo Inca Cuzqueño, con formas y diseños típicos de este estilo, y la que surge como resultado de la propia dinámica incaica en sus provincias o territorios ocupados, que hemos llamado como Inca Regional. Dado que muchas veces el territorio donde se encuentra determinado tipo cerámico excede al territorio aceptado a determinada provincia incaica, es que hemos preferido la denominación de Inca Regional (Vallejo 2004). Las formas y tipos cerámicos que se derivan de la tradición local y que son pertenecientes al estilo Ychsma, son muy numerosos en este periodo y es común hallar en los contextos arqueológicos de esta fase, tanto los elementos locales del Ychsma Tardío B, como los pertenecientes al estilo Inca Cuzqueño (Córdova 2005) y el Inca Regional.

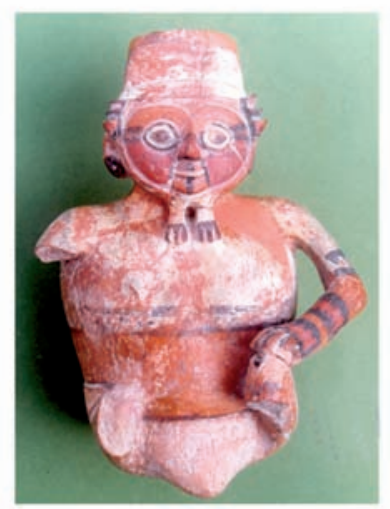

ARMATAMBO

Figura 15. Vasija escultórica procedente de Armatambo (Ruales, Toso y Vallejo 1983).

Figure 15. Sculpted vessel proceeding from Armatambo (Ruales, Toso y Vallejo 1983). 


\section{Conclusiones}

Si bien, hasta hace pocos años, la posibilidad de comprender la situación social y cultural de la región comprendida entre los valles bajos del Rímac y Lurín se encontraba muy limitada por la gran segmentación estilística que existía y por la poca comprensión del proceso secuencial y cronológico de esta, creemos que hoy en día los avances ocurridos en la definición del estilo cerámico existente en esta región, pueden objetivamente conducir a una visión mucho más cercana de esta situación.

En realidad, los resultados de orden social y cultural que se pueden obtener a partir de la definición de una secuencia cerámica son sumamente importantes. Por citar un caso, las anteriores divisiones culturales existentes para esta región basadas en conjuntos cerámicos distintos, eran en concreto, solo distinciones de orden cronológico propias de la dinámica que experimenta un estilo cerámico en su desarrollo en el tiempo. La cerámica como tal, no solo representa una manera de entender a una sociedad a través de su iconografía o producción, sino constituye además herramienta fundamental de ordenamiento cronológico para muchos contextos arqueológicos que aparecen mayormente confusos.

Aunque aún queda mucho tema de discusión, con respecto a la definición final del estilo Ychsma, es claro que los avances producidos en los últimos años están conduciendo a una secuencia cerámica cada vez mas definida y específica, además de comprender a muchas mas formas y tipos cerámicos, anteriormente desconocidos o poco claros, en el corpus cerámico ychsma. Quedan sin embargo, muchas tareas por resolver, como la definición del territorio ychsma y sus áreas periféricas. También es necesario aclarar el aspecto interno de la región ychsma, en el supuesto de que convivan varios grupos étnicos y que estos se expresen en diferencias cerámicas o si estas diferencias correspondan a otras variables sociales o culturales.

Finalmente, la complejidad del periodo Inca, expresada a su vez en la complejidad de los estilos, formas y tipos cerámicos que se presentan en este periodo, puede ser un gran tema de investigación y discusión, enriquecido aun más con los avances tecnológicos aplicables al análisis de la cerámica.

Agradecimientos: Quisiera agradecer especialmente a Luisa Díaz, Directora del Proyecto Arqueológico Armatambo por el apoyo brindado para la realización de este artículo, tanto con el material gráfico proveniente de sus investigaciones, como con sus sugerencias. También deseo agradecer 
a Glenda Pérez, conservadora del Museo de Sitio de Pachacamac, por la edición de las imágenes presentadas.

\section{Notas:}

1 Entre estos se pueden señalar al Proyecto Ychsma dirigido por Peter Eeckhout y Carlos Farfán, el Pachacamac Archaeological Project dirigido por Izumi Shimada y Rafael Segura, el Proyecto Pueblo Viejo dirigido por Krzysztof Makowski y el Proyecto Armatambo dirigido por Luisa Díaz.

El estudio elaborado por Hudtwalker y Pinilla (2004) resulta interesante e importante para comprender la situación cronológica de la isla San Lorenzo, así como las características básicas de los contextos funerarios. Una primera revisión podría situar las evidencias arqueológicas en la época Ychsma Tardío, comprendiendo sus dos fases A y B, es decir, una fase preinca y la siguiente, perteneciente al periodo Inca. Varias preguntas surgen sin embargo: una es si la ocupación ychsma de la isla se inicia decididamente en la época preinca o por el contrario, si las evidencias arqueológicas, aunque asignables estilísticamente a una fase anterior al Horizonte Tardío, son más bien del periodo Inca, dado que también es lógico suponer que en los primeros años de ocupación incaica la cerámica ychsma siguió reproduciéndose de acuerdo con los cánones precedentes.

Por ejemplo, la decoración aplicada de serpientes o culebras es muy común en la cerámica ychsma en su fase final, cuando ocurre el Horizonte Tardío (fase Ychsma Tardío B). En ese proceso los préstamos e influencias de diversos estilos son frecuentes. Sin embargo este motivo, no es del todo claro de dónde provenga o si es originario en la cerámica ychsma. En una fase anterior (Ychsma Tardío A), aparece este motivo pero en posición vertical y generalmente empleado en otro tipo de vasijas.

La aparición y funcionamiento de este curacazgo, está íntimamente ligado con la ampliación hacia el sur del canal de regadío de Surco, ocurrida presumiblemente entre los siglos XI y XII, donde son habilitadas sucesivamente grandes extensiones de tierra cultivable. Antes de la dominación incaica en la costa central, el lugar era conocido con el nombre de Sulco o Surco, que es la denominación de la etnia o población que allí residía. Otro topónimo aún existente, pero que podría correlacionarse igualmente con fases antiguas, es aquel de Marcavilca, que significaría "ciudad o pueblo sagrado».

En la fase Ychsma Temprano B, la cerámica en ambiente reductor aparece también con mayor relevancia. Esta técnica, por supuesto, no fue desconocida entre los ceramistas ychsma y es muy probable que muchos de los especímenes hallados pertenecientes al periodo Inca, en realidad correspondan a la tradición local ychsma en lugar que a la tradición chimú, como aparece a veces en algunos autores (p.e. Makowski y Vega Centeno 2004: Fig. 8 b).

\section{Bibliografía}

Ángeles, R. 2003. Arqueología del valle de Asia. Cuadernos del Patrimonio Cultural 1. Museo Municipal Huaca Malena. Lima.

Ángeles, R. y D. Pozzi-Escot. 2004. "Del Horizonte Medio al Horizonte Tardío en la Costa Sur Central: el caso del valle de Asia". Bulletin de l'Institut Français d'Études Andines 33 (3): 861-886. 
Bazán Del Campo, F. 1990. Arqueología y Etnohistoria de los Periodos Prehispánicos Tardios de la Costa Central del Perú. Tesis de licenciatura. Universidad Nacional Mayor de San Marcos. Lima.

Bonavia, D. 1959. "Cerámica de Puerto Viejo (Chilca)". Actas y trabajos del II Congreso Nacional de Historia del Perú, I: 137-168. Lima.

Bueno, A. 1983. "El antiguo valle de Pachacamac. Espacio, tiempo y cultura (2a parte)". Boletin de Lima 25: 5-27.

Bueno, A. 1991. "La «marca» de Lima Prehispánica”. Espacio 31: 38-43.

Calancha, A. de la. 1974 [1638]. Crónica Moralizadora. Ignacio Prado Pastor. Lima.

Casas, L. y C. Dolorier. 2004. Agricultores y tejedores de Huallamarca. Manuscrito en el Museo de Sitio Huallamarca, Lima.

Córdova, M. 2005. "El Sauce, un cementerio del Horizonte Tardío en San Juan de Lurigancho, Lima”. Corriente Arqueológica 1: 199-221.

Cornejo, M. A. 2000. "La nación Ischma y la provincia inka de Pachacamac". Arqueológicas 24: 149-173.

Cornejo, M. A. 2003. "Sacerdotes y tejedores en la provincia inka de Pachacamac". Boletin de Arqueología PUCP 6: 171-204.

Díaz, L. 2002 Informe del Proyecto Arqueológico de Rescate «La Rinconada Alta». Manuscrito en posesión del autor, Lima.

Díaz, L. 2004. Informe Final del Proyecto Arqueológico de Rescate en los asentamientos humanos San Pedro y 22 de Octubre-Armatambo, Chorrillos. Lima. Manuscrito en posesión del autor, Lima.

Díaz, L. y F. Vallejo. 2002. "Identificación de contextos Ichma en Armatambo". Arqueología y Sociedad 14: 47-75.

Díaz, L. y F. Vallejo. 2003a. "Hallazgo de pirámides con rampa en Armatambo". Medio de Construcción 175: 49-54.

Díaz, L. y F. Vallejo. 2003b. "Armatambo y el dominio incaico en el valle de Lima”. Boletín de Arqueología PUCP 6: 355-374.

Díaz, L. y F. Vallejo. 2005. "Clasificación del patrón funerario Ychsma identificado en Armatambo y La Rinconada Alta". Corriente Arqueológica 1: 223-322. 
Dulanto, J. 2001. “Dioses de Pachacamac: el ídolo y el templo”. En Los Dioses del antiguo Perú, vol. II, compilado por K. Makowski, pp: 159-181. Colección Arte y Tesoros del Perú. Banco de Crédito del Perú. Lima.

Duviols, P. 1967. "Un inédit de Cristóbal de Albornoz: la instrucción para descubrir todas las guacas del Pirú y sus camayos y haziendas". Journal de la Société des américanistes, 56(1), 7-39. París.

Eeckhout, P. 1995. "Pirámide con rampa No 3 de Pachacamac, costa central del Perú. Resultados preliminares de la primera temporada de excavaciones (zonas 1 y 2)". Bulletin de l'Institut Français d'Études Andines 24 (1): 65-106.

Eeckhout, P. 1999. Pirámide con rampa No III, Pachacamac. Nuevos datos, nuevas perspectivas". Bulletin de l'Institut Français d'Études Andines 28 (2): $169-214$.

Eeckhout, P. 2004. "Relatos míticos y prácticas rituales en Pachacamac". Bulletin de l'Institut Français d'Études Andines 33 (1): 1-54.

Eeckhout, P. (ed.). 2004. "Arqueología de la costa central del Perú en los periodos tardíos". Bulletin de l'Institut Français d'Etudes Andines 33 (3).

Engel, F. 1984. Prehistoric Andean Ecology. Man, Settlement and Environment in the Andes, Chilca. Centro de Investigación de Zonas Áridas (CIZA) de la Universidad Nacional Agraria del Perú. New York.

Feltham, J. y P. Eeckhout. 2004. "Hacia una definición del estilo Ychsma: aportes preliminares sobre la cerámica Ychsma tardía de la pirámide III de Pachacamac". Bulletin de l'Institut Français d'Études Andines 33 (3): 643-679.

Franco, R. 1993."Los dos templos principales de Pachacamac. Breve síntesis". Revista del Museo de Arqueología 4: 55-77.

Franco, R. 1998. La pirámide con rampa no 2 de Pachacamac. Excavaciones y nuevas interpretaciones. $105 \mathrm{p}$. Trujillo.

Franco, R. 2004. "Poder religioso, crisis y prosperidad en Pachacamac: del Horizonte Medio al Intermedio Tardío”. Bulletin de l'Institut Français d'Etudes Andines 33 (3): 465-506.

Franco, R. y P. Paredes. 2001. "El Templo Viejo de Pachacamac. Nuevos aportes al estudio del Horizonte Medio". Boletín de Arqueología PUCP 4: 607-630. 
Guerrero, C. 2004. "Cronología cerámica y patrones funerarios del valle del Rímac: una aproximación a los periodos tardíos". En Puruchuco y la sociedad de Lima: Un homenaje a Arturo Jiménez Borja, editado por L. F. Villacorta (ed.), pp: 157-177. Consejo Nacional de Ciencia y Tecnología-CONCYTEC. Lima.

Horkheimer, H. 1970. "Chancay prehispánico: diversidad y belleza”. En 100 años de arqueología en el Perú, editado por R. Ravines, pp: 363378. Instituto de Estudios Peruanos. Lima.

Hudtwalcker, J. y J. Pinilla. 2004. "Proyecto Arqueológico San Lorenzo 2003-2004”. Revista de Marina 97 (2): 55-64.

Hyslop, J. y E. Mujica. 1992. "Investigaciones de A.F. Bandelier en Armatambo (Surco)". Gaceta Arqueológica Andina VI (22): 63-86.

Iriarte, F. 1960. "Algunas apreciaciones sobre los huanchos". En Antiguo Perú. Espacio y Tiempo, editado por R. Matos Mendieta, pp: 259-263. Editorial Juan Mejía Baca. Lima

Isla, J. 1995. "Materiales recuperados por Max Uhle (1906-1907) en la Isla de San Lorenzo, costa central del Perú". Gaceta Arqueológica Andina 24: 73-91.

Jiménez Borja, A. 1985. "Pachacamac". Boletín de Lima 38: 40-54.

Makowski, K. 2003. "Arquitectura, estilo e identidad en el Horizonte Tardío: el sitio de Pueblo Viejo-Pucará, valle de Lurín". Boletín de Arqueología PUCP 6: 137-170.

Makowski, K. y M. Vega Centeno. 2004. "Estilos regionales en la Costa Central en el Horizonte Tardío. Una aproximación desde el valle de Lurín". Bulletin de l'Institut Français d'Études Andines 33 (3): 681714.

Menzel, D. 1968. La cultura Huari. Compañía de Seguros y Reaseguros Peruano-Suiza, Lima.

Meyers, A. 1975. "Algunos problemas en la clasificación del estilo incaico". Pumapunku 8: 7-25.

Narváez, J. J. 2006. Sociedades de la antigua ciudad de Cajamarquilla. Investigaciones arqueológicas en el Sector XI del Conjunto Tello y un estudio de la colección tardía del Conjunto Sestieri. Auqi Ediciones, Lima.

Paredes, P. 1988. "Pachacamac-Pirámide con rampa no 2". Boletín de Lima 55: 41-58. 
Paredes, P. y R. Franco.1987. "Pachacamac: Las pirámides con rampa, cronología y función”. Gaceta Arqueológica Andina 13: 5-7.

Paredes, P. y J. Ramos. 1994. "Excavaciones arqueológicas en el sector Las Palmas, Pachacamac". Boletín de Lima 91-96: 313-349.

Ravines, R. 2000. "Canto Chico, asentamiento prehispánico del valle del Rímac”. Boletín de Lima XXII (119-122): 93-290.

Rea, C. 2001. Proyecto de Investigaciones Arqueológicas y Puesta en Valor de la Huaca San Borja. Instituto Nacional de Cultura, Lima.

Rostworowski, M. 1972. "Breve ensayo sobre el señorío de Ychma o Ychima”. Arqueología PUC 13: 37-51.

Rostworowski, M. 1978 Señoríos indígenas de Lima y Canta. Instituto de Estudios Peruanos, Lima.

Santillán, H. de. 1968 [1563]. Relación del origen, descendencia, política y gobierno de los Incas. En Biblioteca Peruana, primera serie, III. 377-463. Editores Técnicos Asociados, Lima.

Schmidt, M. 1929. Kunst und Kultur von Peru. Impropyläen - Verlag, Berlín.

Shimada, I., R. Segura, M. Rostworowski y H. Watanabe. 2004. "Una nueva evaluación de la Plaza de los Peregrinos de Pachacamac: aportes de la primera campaña 2003 del Proyecto Arqueológico Pachacamac". Bulletin de l'Institut Français d'Études Andines 33 (3): 507-538.

Strong, W. D. y J. M. Corbett. 1943. "A ceramic sequence at Pachacamac". Columbia Studies in Archeology and Ethnology I (2): 27-121.

Tantaleán, H. y O. Pinedo. 2004. "Entre los Andes y el Mar: El valle bajo de Mala antes y durante la ocupación inca”. Revista de Arqueología del siglo XXI 283: 54-63.

Tello, J. C. 1999. Arqueología del Valle de Lima. Cuadernos de Investigación del Archivo Tello 1. Museo de Arqueología y Antropología de la Universidad Nacional Mayor de San Marcos, Lima.

Ubbelohde-Doering, H. 1952. El Arte en el Imperio de los Incas. Editorial Gustavo Gili, Barcelona.

Uhle, M. 1903. Pachacamac. Report of the William Pepper, M. D., LL. D., Peruvian Expedition of 1896. Department of Archaeology, University of Pennsylvania. Philadelphia. 
Vallejo, F. 1988. "Ritos funerarios en el Perú Prehispánico. Análisis de una tumba del complejo funerario de Armatambo, Lima". En Ande: Prehistoria Come Progetto. Documenti de Etno-Archaeología Precolombiana, editado por M. Lunghi, pp: 381-443. Universitá Católica dil Sacro Cuore. Brescia.

Vallejo, F. 2004. "El estilo Ychsma: características generales, secuencia y distribución geográfica". Bulletin de l'Institut Français d'Etudes Andines 33 (3): 595-642.

Vallejo, F. 2005. Informe de la Puerta de Pachacamac: Estudio arqueológico $e$ iconográfico. Museo de sitio Pachacamac. Instituto Nacional de Cultura, Lima.

Willey, G. 1943 "A supplement to the pottery sequence at Ancon". Columbia Studies in Archeology and Etnology, I (4): 197-211. Columbia University Press, New York. 